\title{
OS IMPACTOS DAS PRÁTICAS COMERCIAIS DA EMPRESA DE COSMÉTICOS NATURA NA COMUNIDADE QUILOMBOLA DO JACAREQUARA EM SANTA LUZIA DO PARÁ-PA
}

\author{
Alessandra Damasceno de Almeida ${ }^{1}$ \\ Arthur Boscariol da Silva ${ }^{2}$
}

\begin{abstract}
RESUMO
O presente artigo analisa as práticas comerciais estabelecidas entre a empresa de cosméticos Natura e a comunidade quilombola denominada Jacarequara, localizada do município de Santa Luzia do Pará, nordeste do estado do Pará, apontando a parceria comercial entre a empresa e a comunidade que desenvolve-se pela comercialização da amêndoa do murumuru (Astrocaryum murumuru Mart). Esta amêndoa é coletada da floresta pelos quilombolas e vendida à empresa para a produção de cosméticos como sabonetes, hidratantes, óleo corporal, entre outros. Com isso, busca-se compreender esta parceria comercial a partir do regime de acumulação flexível no século XXI e seus desdobramentos no espaço geográfico. Para isso, é necessário compreender a parceria comercial entre a empresa Natura, que circula em um mercado global com uma comunidade quilombola que possui cultura e relações de produção de específicas. Este debate tem como objetivo verificar as implicações socioespaciais ocasionadas pela parceria comercial com a empresa na organização do espaço geográfico. O que se observou neste estudo são práticas comerciais contemporâneas que ainda não alteraram por completo o modo de vida de uma sociedade tradicional. As mudanças identificadas apontam que existem famílias que decidiram pela participação das atividades, alterando sua dinâmica de vida e afetando suas práticas produtivas tradicionais.
\end{abstract}

Palavras chaves: Natura. Santa Luzia do Pará. Quilombola. Comunidades tradicionais.

\begin{abstract}
This article analyzes the commercial practices established between the Natura cosmetics company and the quilombola community called Jacarequara, located in the municipality of Santa Luzia do Pará, northeast of the state of Pará, pointing out the commercial partnership between the company and the community that develops by the marketing of the murumuru almond (Astrocaryum murumuru Mart). This almond is collected from the forest by the quilombolas and sold to the company for the production of cosmetics such as soaps, moisturizers, body oil, among others. With this, it is sought to understand this commercial partnership from the regime of flexible accumulation in the XXI century and its unfolding in the geographical space. For this, it is necessary to understand the commercial partnership between the company Natura, which circulates in a global market with a quilombola community that has specific culture and production relations. This debate aims to verify the sociospatial implications caused by the commercial partnership with the company in the organization of the geographical space. What has been observed in this study are contemporary commercial practices that have not yet completely changed the way of life of a traditional society. The changes identified indicate that there are families that decided to participate in activities, changing their life dynamics and affecting their traditional productive practices.
\end{abstract}

Keywords: Natura. Santa Luzia do Pará. Globalization. geographic space production.

\footnotetext{
${ }^{1}$ Pós-Graduanda em Ciências Ambientais e Desenvolvimento Sustentável na Amazônia pelo Instituto Federal de Educação, Ciência e Tecnologia do Pará/ Campus Bragança. alessa.da@hotmail.com

${ }^{2}$ Mestre em Geografia. Professor com dedicação exclusiva do Instituto Federal de Educação, Ciência e Tecnologia do Pará /Campus Bragança. arthurbss@gmail.com
} 


\section{INTRODUÇÃO}

A comercialização de produtos florestais não madeireiros tem sido uma proposta frequente entre empresas de cosméticos e comunidades tradicionais na Amazônia. Essa parceria vislumbra, em tese, promover a conservação ambiental e melhorar o padrão de vida de comunidades tradicionais. Com base neste argumento, a empresa de cosméticos Natura se instalou na mesorregião do Nordeste Paraense. A comercialização dos produtos florestais é feita através de relações comerciais conhecidas como "parcerias" entre comunidades tradicionais e empresa. Esse crescimento se deu devido à demanda crescente por produtos ditos "sustentáveis" e socialmente responsáveis.

Neste cenário, a Amazônia representa a principal plataforma para acordos comerciais de cunho sustentável no mundo, dado seu grau de preservação e exotismo. Várias iniciativas baseadas em abordagens ligadas ao comércio "verde" ou "solidário" estão em andamento na região, abrangendo diversos setores e produtos, como óleos essenciais e plantas medicinais (MORSELLO, 2004). Portanto, é pertinente investigar quais as oportunidades e impactos gerados por essas parcerias comerciais no que diz respeito às relações socioespaciais das comunidades tradicionais da Amazônia, ao meio ambiente e à sociedade como um todo. Estas questões tornam-se oportunas para compreendermos o atual papel da Amazônia e das sociedades tradicionais no cenário global de produção capitalista.

O modelo de parcerias comerciais entre empresas de cosméticos e comunidades tradicionais na Amazônia vem sendo apresentado para a sociedade como uma iniciativa capaz de promover o "desenvolvimento sustentável", devido essas atividades extrativistas conciliarem uma exploração produtiva da floresta, com a própria preservação ambiental e a valorização das populações tradicionais. Porém, pouco se sabe sobre as potencialidades, limitações e os efeitos que as parcerias comerciais causam nas relações socioespaciais das comunidades tradicionais envolvidas na parceria comercial.

As populações tradicionais, segundo Diegues (2001), são aquelas que se organizam em agrupamentos específicos onde a natureza exerce papel relevante na definição e desenvolvimento do modo de vida. Assim, associado às condições do respectivo espaço geográfico, o modo de vida resulta no desenvolvimento de conhecimentos profundos dos ciclos biológicos e das dinâmicas naturais que regem seu espaço. Assim, cada comunidade acaba construindo uma cultura própria ao desenvolver técnicas adaptadas às suas necessidades de vida. 
Neste trabalho, considera-se que os territórios das comunidades tradicionais são fruto das relações socioespaciais de seus antepassados. Essas relações específicas são reproduzidas e influenciadas por novos contextos, sendo que a preservação dos princípios identitários é mais fortemente manifestada nessas comunidades. Sendo assim, não podem ser compreendidas a partir de generalizações importadas de outras áreas (DIEGUES, 2001).

Essa pesquisa tem como foco compreender quais as implicações nas relações socioespaciais na comunidade quilombola Jacarequara, localizada no município de Santa Luzia do Pará, no nordeste do estado do Pará, a partir da parceria comercial com a empresa de cosméticos Natura. Esta parceria para comercialização de Produtos Florestais Não Madeireiros (PFNM's) foi idealizada e viabilizada por membros da Cooperativa Mista dos Agricultores entre os Rios Caeté e Gurupi (COOMAR) baseado na coleta e comercialização da amêndoa do murumuru. Com isso, pode-se identificar as transformações resultantes da parceria comercial com a empresa Natura e relacionar-se os principais pontos das transformações na comunidade.

Defende-se a hipótese de que o envolvimento de comunidades tradicionais nessas parcerias comerciais pode, na verdade, desestruturar as bases tradicionais de organização das comunidades, capturando-as e tornando-as reféns de decisões externas à sua realidade cotidiana, rompendo a relativa autonomia deste território, transformando-o num território mais heterônomo (SOUZA, 2000). Essa hipótese é levantada a partir das mudanças nas relações socioespaciais entre os quilombolas e na organização de um novo modo de produção pautado na coleta e comercialização do murumuru.

A inserção de uma nova produção que é gerida pela lógica de mercado global e que facilita cada vez mais a circulação monetária vêm introduzindo novos bens de consumo e refletindo em novos valores nas relações sociais estabelecidas na comunidade. Assim, verifica-se nas comunidades tradicionais a ocorrência de um processo de mercantilização das relações produtivas, em detrimento das bases solidárias de organização comunitária: uma estratégia de sobrevivência historicamente consolidada nas populações tradicionais quilombolas (MORSELLO, 2004). Assim, neste modelo de parcerias comerciais sustentáveis, podemos dizer que estas são pautadas num modelo de desenvolvimento que não preserva as relações existentes antes de sua chegada, transformando-as ao favor da empresa.

A comunidade Jacarequara, anteriormente pertencente ao município de Ourém, localiza-se às margens do Rio Guamá. O território da comunidade apresenta registros que datam do período da escravidão negra na Amazônia, conforme trata Castro (2006, p. 16): "há 
registro de muitos quilombos, sendo bem conhecidos os de Ourém, Turiaçú e Bragança que atravessam as terras e a fronteira do Pará e Maranhão [...]".

Nessas comunidades, os aquilombados constituíam práticas socioespaciais de uma vida comum: realizavam festas, plantavam, coletavam, pescavam, caçavam e praticavam transações econômicas possíveis. Estabeleciam nos quilombos os espaços políticos, econômicos, sociais e culturais (PINTO, 2004, p. 50). Neste contexto, o ambiente é o espaço de produção de grande importância na reprodução do grupo, uma vez que o mesmo está diretamente ligado a cada um desses aspectos.

As condições de exploração do ambiente e as relações produtivas foram e ainda são aliadas dos moradores do Jacarequara, pois é do ambiente que se extraia praticamente tudo que era necessário para a sobrevivência. Da floresta e da mata ciliar se extraem frutos como o buriti, a castanha, o jenipapo, o açaí, a bacaba, e, mais recentemente, a amêndoa do murumuru. É também nestas áreas que se caça, tiram as raízes comestíveis, ervas medicinais, cipós, palhas, bem como o barro e a madeira que serviam (e servem) para fazer suas casas. Do rio tira-se uma grande variedade de pescados. Também dependiam (e dependem) da terra para fazer seus roçados, onde cultivavam desde cana de açúcar até várias espécies de grãos, como arroz, feijão, milho, café e alguns tubérculos, como a mandioca, a batata doce e o cará. Em suma, "[...] pode-se constatar que os modos de produção que garantiam a reprodução dos aquilombados são os produtos retirados da floresta e seus recursos naturais" (ALMEIDA, 2009, p. 29). Algumas dessas práticas, no entanto, vêm reduzindo nos últimos anos.

A relação do homem com a natureza existente na comunidade do Jacarequara desde o surgimento do quilombo era marcada por relações mais harmônicas com a dinâmica natural daquele espaço. Estas relações mais aproximadas com essa dinâmica resultam na escolha “[...] daquelas suas partes ou aspectos considerados fundamentais ao exercício da vida, valorizando, diferentemente, segundo os lugares e as culturas, essas condições naturais que constituíam a base material da existência do grupo" (SANTOS, 2009, p. 235). Esta heterogeneidade das interações entre homem e natureza são, de um modo geral, homogeneizadas pelas relações comerciais estabelecidas com a Natura, marcadas por outra métrica e outra temporalidade: a do modo de produção capitalista. E é na busca destas alterações que este trabalho está assentado.

Esta pesquisa foi realizada entre 2011 e 2015, utilizando-se de revisão bibliográfica de cunho teórico, observação sistemática, diálogo com os quilombolas e consulta do acervo das entrevistas em anexos dos resultados da pesquisa de Almeida (2009). Esta pesquisa possui 
uma análise de como os moradores do Jacarequara se relacionavam entre si e com a natureza desde suas origens e que foram repassados a cada geração do grupo.

Neste período observou-se que as práticas comerciais na comunidade do Jacarequara, conduzidas pela introdução dinâmica produtiva motivada pela Natura, empresa de cosméticos de capital aberto baseada no capital global e flexível, está provocando alterações nas relações sociais dos quilombolas com a natureza. Georges Benko (2002) discute as transformações das atividades econômicas das empresas de acúmulo de capital flexível no século XXI e seu novo comportamento espacial, resultado do processo de reestruturação do regime de acumulação do capitalismo. Entende-se que a parceria comercial entre a empresa Natura e a comunidade quilombola em questão é parte deste processo.

$\mathrm{Na}$ Amazônia, a parceria comercial entre a empresa de cosméticos Natura e as comunidades tradicionais tem sido cada vez mais comum devido as suas ações socioambientais para o desenvolvimento local e a tendência de valorização dos produtos ambientalmente "corretos". Assim, a Natura busca essas parcerias com o objetivo de atingir esta parcela do mercado, visando a obtenção de lucro por conta o alto valor agregado do produto e dos baixos custos de aquisição dos PFNM's.

\section{POPULAÇÕES TRADICIONAIS: BREVES COMENTÁRIOS}

Para melhor contribuir na análise deste trabalho, ressalta-se a necessidade de compreender mais a fundo a definição do conceito de população tradicional. Segundo Arruda,

[As populações tradicionais] apresentam um modelo de ocupação do espaço e uso dos recursos naturais voltados principalmente para a subsistência, com fraca articulação com o mercado, baseado em uso intensivo de mão de obra familiar, tecnologias de baixo impacto derivado de conhecimentos patrimoniais e, normalmente, de base sustentável [...] Em geral, ocupam a região há muito tempo e não tem registro legal da propriedade privada individual da terra, definindo apenas o local de moradia como parcela individual, sendo o restante do território encarado como área de utilização comunitária, com seu uso regulamentado pelo costume e por normas compartilhadas internamente (ARRUDA, 1999, p. 79-80).

O conceito de Arruda (1999) é bastante amplo e teve uma ampla contribuição para os estudos das diversas formas de existência das comunidades tradicionais da Amazônia, não as restringindo apenas para as comunidades indígenas e quilombolas.

Outra importante contribuição na definição deste conceito é a de Cunha e Almeida (2001), que definem que o termo a ser utilizado ainda é bastante genérico e está em construção, classificando-os como um conceito abrangente, assim como o de Arruda (1999). 
Segundo os autores, podemos considerar entre os sujeitos os extrativistas, seringueiros, castanheiros, quebradeiras de coco de babaçu, ribeirinhos, pescadores artesanais, pantaneiros, dentre tantos outros que se identificam como populações tradicionais.

Apesar de formular uma definição semelhante à de Arruda (1999), Lima e Pozzobon (2005) ampliam o conceito em questão, refinando-o na medida em que enumeram diversas evidências do porquê destas populações tradicionais apresentarem um impacto ambiental diferente das sociedades "modernizadas": seus modos de vida objetivam a subsistência e geram com baixo impacto tecnológico.

Outro autor a ser citado para contribuir na análise deste conceito é Diegues (1993, 1997), que demonstra como essas populações tradicionais desenvolvem um modo de vida de integração com a natureza. Para este autor, as populações tradicionais vivem em harmonia com a natureza, articulando o seu modo de vida com os recursos naturais, desenvolvendo uma cultura de vasto conhecimento dos mesmos.

Para Diegues (2002), populações tradicionais são aquelas que praticam um extrativismo que foi historicamente construído, caracterizando-se por um manejo florestal de baixo impacto ambiental. Em relatório realizado em parceria com outros autores para o Ministério do Meio Ambiente (MMA), Diegues define sociedades tradicionais como:

\footnotetext{
Grupos humanos culturalmente diferenciados que historicamente reproduzem seu modo de vida, de forma mais ou menos isolada, com base em modos de cooperação social e formas específicas de relações com a natureza, caracterizadas tradicionalmente pelo manejo sustentado do meio ambiente. Essa noção se refere tanto a povos indígenas quanto a segmentos da população nacional que desenvolveram modos particulares de existência, adaptados a nichos ecológicos específicos (DIEGUES et al, 2000, p. 37).
}

Os quilombolas também se enquadram como populações tradicionais, pois estes grupos desenvolvem um modo de vida historicamente na mesma região, com modos de cooperação social entre si e uma relação específica do modo de uso da natureza. Nesse sentido, pode-se considerar a comunidade quilombola do Jacarequara como sendo uma comunidade tradicional, de acordo com os critérios utilizados pelo autor e adotados neste artigo. E é com estas comunidades tradicionais que se dão as práticas comerciais estudadas neste artigo. 


\section{A INSERÇÃO DAS COMUNIDADES TRADICIONAIS NO PROCESSO DE ACUMULAÇÃO GLOBALIZADO: PRÁticAS COMERCIAIS NA AMAZÔNIA BRASILEIRA}

Este arranjo particular de parcerias entre empresas e comunidades tradicionais surgiu nas últimas décadas, mais especificamente no final da década de oitenta, baseados na crescente demanda por produtos supostamente produzidos e comercializados de maneira social e ambientalmente sustentável.

Georges Benko (2002) em sua obra Economia Espaço e Globalização: Na aurora do século XXI, contribui com a análise das mutações econômicas e políticas, com ênfase no campo da industrialização contemporânea, pois esta tem em seu bojo uma carga de alta tecnologia que, por consequência, altera na organização social e territorial do capitalismo contemporâneo. Este cenário é o pano de fundo das estratégias das empresas no cenário de acumulação do capital flexível, as quais se adequam às exigências do mercado, preocupandose com o acesso ao fornecimento de matéria prima, articulando-se à estas.

\footnotetext{
A organização flexível da empresa apresenta vários aspectos fundamentais. Ante a necessidade de se adaptarem, as empresas têm a faculdade de agir sobre os efetivos (o que se denomina de flexibilidade numérica) ou sobre tarefas que lhes confiam (flexibilidade funcional) (BENKO, 2002, p. 31).
}

A metodologia de análise do regime de acumulação flexível expressa por Benko (2002) está fundamentada de forma particular nas mudanças espaciais da economia, pois esta metodologia traz uma apresentação sintética que possibilita a compreensão a organização territorial do capitalismo na produção contemporânea no fenômeno da globalização. Com isso, entendemos que as estratégias de produção e reprodução do capital investido na Amazônia pela empresa Natura está inserido neste cenário, sendo que a empresa está estrategicamente instalada na região para obter mais facilidade no acesso à matéria prima para produção de seus cosméticos.

O surgimento de mercados consumidores em busca de produtos rotulados como "verdes" e "justos", aliado ao crescimento das políticas corporativas de responsabilidades socioambientais, tornou este arranjo cada vez mais comum nas florestas tropicais, inclusive na Amazônia brasileira (MORSELLO, 2002).

Estudos de valoração das florestas tropicais demonstraram, ao menos teoricamente, a viabilidade econômica da exploração de Produtos Florestais Não Madeireiros (PFNM's) por comunidades tradicionais (PETERS et al, 1989). Desde então, são crescentes os estudos 
advogando os benefícios da comercialização de PFNM's, dando início a uma verdadeira onda de projetos e iniciativas em pesquisas na Amazônia brasileira.

A exploração de PFNM's por comunidades tradicionais pode se estruturar de diversas maneiras, desde produtores individuais buscando mercados regionais, até várias comunidades se organizando em associações ou cooperativas para exportar seus produtos. No caso da comunidade do Jacarequara, a comercialização do murumuru em amêndoa é feita a partir da organização com outras comunidades quilombolas, também do município de Santa Luzia do Pará, que estão vinculadas à Cooperativa Mista dos Agricultores entre o Rio Caeté e o Gurupi (COOMAR) para formalizar a venda via contrato com a Natura.

Contudo, a inserção das comunidades tradicionais da Amazônia na economia de mercado por meio da comercialização de produtos coletados da floresta pode causar impactos sociais, econômicos ou culturais nas comunidades envolvidas, além de transformações nos ecossistemas explorados (MORSELLO, 2004). Um dos aspectos mais destacados é a transformação no uso tradicional dos recursos naturais, que ocorre em função da passagem da exploração dos recursos naturais regida pela lógica da subsistência, para um modo de exploração regido pela lógica do mercado. Segundo Morsello (2002), essas transformações podem causar impactos na substituição parcial ou até mesmo completa no abandono de práticas de subsistência econômica e social tradicionais.

As parcerias comerciais estabelecidas entre empresas e comunidades tradicionais para a comercialização de PFNM's estão se tornando um tipo de relação cada vez mais frequente na Amazônia brasileira. Estudos que busquem identificar os impactos da inserção no mercado de comunidades tradicionais por meio dessa parceria tornam-se relevantes e oportunos.

\section{AS RELAÇÕES SOCIOAMBIENTAIS NA COMUNIDADE DO JACAREQUARA}

Nas margens do rio Guamá, os negros aquilombados do Jacarequara caçavam, pescavam, coletavam e praticavam agricultura para garantir a reprodução do grupo e, com isso, obtinham os utensílios básicos para viverem. Em alguns casos havia a produção de excedentes para comercialização, revelando formas de sobrevivência dos quilombolas da comunidade. A parceria comercial com a empresa Natura altera as relações de produção anteriormente ancoradas na cooperação e no trabalho familiar. Conforme entrevista realizada por Almeida (2009, p. 82)

Há de primeira era assim, cada um escolhia um pedaço de terra e brocava e queimava, e assim cada ano era uma nova área, porque aquela de antes não dava 
mais, hoje todo mundo se reúne e arada um único local e todo mundo planta no mesmo lugar cada um com a sua tarefa de terra. Hoje em dia tem o pessoal que trabalha na prefeitura, parece que são oito, tem um pouco ainda de peixe, caça quase não existe mais, a principal maneira de sobrevivência é a agricultura (Entrevistado: José do Livramento Nogueira, 31 anos, agricultor, 15/11/08).

Diante da análise do relato acima e o trabalho de campo realizado pelos autores deste artigo, é possível compreender que a relação do homem com a natureza se dava em caminhos diferentes dos atuais, onde percebe-se a divisão dos lotes para plantio e a redução de atividades como a caça e a pesca. É a partir dos últimos anos que se observam as mudanças relação do homem com a natureza na comunidade quilombola, perdendo a origem do relacionamento entre os moradores e com os recursos que a natureza oferece para a comunidade.

Tais modificações no modo tradicional de vida da comunidade ocorrem, entre outros motivos, devido à inserção da Natura como um novo agente, interferindo na organização estrutural dos modos de produção desenvolvidos pelos aquilombados. Observaram-se transformações sociais, como a diminuição de atividades de cooperação em mutirões na formação do roçado. Segundo relatos, esta era uma das atividades mais corriqueiras para a realização de produção agrícola. Estes relatos também apontam que esta prática passou a ser pouco desenvolvida devido alguns moradores se dedicarem ao extrativismo, mais especificamente, à coleta da amêndoa do murumuru.

Esta atividade inaugura uma nova forma de apropriação dos recursos da natureza, incutindo novo sentido nesta amêndoa pela comercialização da mesma com a empresa Natura. A palmeira murumuru faz parte da família botânica Palmae, sendo seu nome científico Astrocaryum murumuru Mart. A coleta da amêndoa é realizada de maneira manual na floresta pelos quilombolas e é comercializada pela empresa através da transação da compra. Para facilitar o relacionamento institucional com a empresa Natura, os quilombolas realizam a venda da amêndoa via contrato prévio realizado com a COOMAR.

$\mathrm{O}$ quadro abaixo apresenta os principais fornecedores rurais parceiros da empresa Natura, Pará.

Quadro 1. Fornecedores rurais parceiros da empresa Natura e municípios sede em 2008

\begin{tabular}{|l|l|}
\hline \multicolumn{1}{|c|}{ Fornecedores Rurais Representados } & \multicolumn{1}{c|}{ Município / UF } \\
\hline CAMTA & Tomé-Açu / PA \\
\hline CART & Cametá / PA \\
\hline CAEPIM & Igarapé-miri / PA \\
\hline COFRUTA & Abaetetuba / PA \\
\hline ASSOCIAÇÃO UNIDOS VENCEREMOS & Santo Antônio do Tauá / PA \\
\hline
\end{tabular}




\begin{tabular}{|l|l|}
\hline COPOAM & Medicilândia / PA \\
\hline COOMAR & Santa Luzia do Pará / PA \\
\hline ASSOCIAÇ̃̃O JAUARI & Moju / PA \\
\hline NOVA OLINDA & Igarapé Açu / PA \\
\hline FECAT & Marabá / PA \\
\hline
\end{tabular}

Fonte: Adaptado de Costa, (2009).

O Quadro 1 apresenta as parcerias comerciais entre a Natura e as comunidades no Pará, inclusive a participação da COOMAR, representante da comunidade Jacarequara desde o ano de 2008. É importante enfatizar que as atividades de produção desenvolvidas na comunidade com o extrativismo do murumuru ainda tem caráter de subsistência e de reprodução do grupo e não a geração de lucro e exploração de mão-de-obra alheia, como mostra (OLIVEIRA, 2007), alterando-se apenas a forma de comercialização de um novo produto respeitando as exigências de mercado. Durante os trabalhos de campo, o que se tem observado é uma constante modificação das relações sociais entre os aquilombados nas atividades de extrativismo na floresta de forma.

\section{A INSERÇÃO DA LÓGICA COMERCIAL DA EMPRESA NATURA NA COMUNIDADE JACAREQUARA}

A inserção da empresa de cosméticos Natura na comunidade Jacarequara ocorre sob o discurso de sustentabilidade ambiental dos recursos naturais da Amazônia. Este discurso, no entanto, precisa ser analisado colocando em questão o entendimento do termo sustentabilidade ambiental.

Para tratarmos de desenvolvimento sustentável sob um ponto de vista ecológico, necessariamente temos de levar em consideração outras condições necessárias para que a sustentabilidade seja eficiente: a dimensão econômica, a dimensão social e a dimensão ambiental (BOFF, 2012). Segundo Boff (2012), é a partir dessa relação imbricada dessas três dimensões que podemos desenvolver modelos de produção sustentáveis.

Os modelos atuais de sustentabilidade são frutos de uma pressão mundial sobre os governos e as empresas em razão da crescente degradação da natureza. O clamor mundial acerca dos riscos ambientais também pesa sobre a vida humana para que todos os esforços possam conferir a sustentabilidade da Amazônia.

Nesse sentido, a lógica de acumulação de capital na Amazônia sob a prática de desenvolvimento de uma produção sustentável está levando a nível global a mercantilização dos recursos naturais da floresta amazônica e os saberes típicos das comunidades tradicionais, 
agora também mercantilizados e estereotipados. Segundo Costa e Richetti (2010), a parceria entre empresa e comunidade tradicional garante para o capital o monopólio da renda através da posição privilegiada que a empresa tem no mercado, pelo valor associado às questões culturais, ambientais e regionais dos produtos, garantindo sua marca num cenário da globalização e se firmando enquanto empresa que anuncia um desenvolvimento sustentável para a Amazônia.

O período atual, provavelmente mais que qualquer outro, oferece essa forma de exercício do poder, pois sob égide da globalização neoliberal, e principalmente nas duas últimas décadas, amparadas pela crise ambiental, o capitalismo encontra novas bases de acumulação, em que tenta ocultar não apenas os conflitos ambientais, mas também os sociais (COSTA; RICHETTI, 2010, p. 255).

Assim, os autores apontam que frente a essa crise ambiental, o capitalismo se reinventa e, ao invés de entrar em conflito com as questões ambientais que eventualmente possam dificultar sua expansão, se apropria da discussão ambiental de maneira superficial, pautada em modelos de desenvolvimento que não atendem aos interesses das comunidades, mas sim das empresas. Sendo a empresa Natura uma empresa de capital aberto, com ações comercializadas em bolsas de valores, a definição de seus valores, metas e projetos são definidos pelo dito "mercado". A saber, os mais fracos desta relação são as comunidades.

Entendemos, assim, que relação criada entre a empresa de cosméticos Natura e as comunidades tradicionais são exemplos desse contexto, revelando como o capitalismo se reinventa e reordena as relações socioespaciais tradicionais para atender seus interesses de acumulação. Não é possível aqui discutirmos os impactos destas ações em escala global, mas as análises e os trabalhos de campo apontam para essas mudanças na escala local.

A parceria comercial entre a empresa de cosméticos Natura e a comunidade Jacarequara acontece via contrato de compra e venda. Este contrato é realizado entre a cooperativa COOMAR, quem realiza o contrato direto com a Natura. As amêndoas coletadas pelos quilombolas são entregues à cooperativa, responsável por receber o valor do produto. Segundo Marcio da Silva Ramos, ex-presidente da COOMAR, entrevistado em julho de 2011, ele foi o pioneiro em manter contato com a empresa a fim de expandir a variedade de produtos fornecidos pelos agricultores da região e entrou em contato com empresa para fornecer produtos de seu interesse. A parceria entre COOMAR e comunidades tradicionais da região começou em 2008. Algumas comunidades, como a do Jacarequara, tinham membros associados na mesma. Após a parceria e com o decorrer dos resultados positivos na parceria 
ocorreu à adesão de novos sócios na cooperativa. A expansão das atividades de coleta é revelada pelos dados abaixo da Tabela 1.

Tabela 1. Evolução da comercialização da amêndoa do murumuru pela COOMAR com a empresa de cosméticos Natura entre os anos de 2008 e 2014

\begin{tabular}{cccccccc}
\hline Ano & 2008 & 2009 & 2010 & 2011 & 2012 & 2013 & 2014 \\
\hline $\begin{array}{c}\text { Amêndoa } \\
\text { do } \\
\begin{array}{c}\text { murumuru } \\
(\mathrm{Kg})\end{array}\end{array}$ & 465 & 2.853 & 12.759 & 30.770 & $36.067^{3}$ & 3.600 & 10.000 \\
\hline
\end{tabular}

Fonte: Questionário aplicado pela autora, junho e julho de 2015.

Assim, como mostra a tabela, os resultados foram crescentes, chegando ao ponto de exceder a capacidade de armazenamento de matéria prima no ano de 2012. A meta para 2015 era de aumentar a quantidade da entrega até o fim do ano. Representantes da COOMAR ressaltam que com o aumento na entrega da amêndoa do murumuru, os agricultores não deixaram de vender seus produtos da agricultura familiar, apenas diminuíram na diversidade de produção. A parceria entre empresa e cooperativa ocorre devido a cooperativa ter CNPJ regularizado para fazer acordos comerciais com empresas, ficando como responsabilidades dos coletores apenas a entrega da amêndoa na COOMAR para ser transportada para a Natura, localizada na cidade de Benevides, Pará.

O objetivo da COOMAR com a parceria era garantir no mercado produtos não agrícolas dos agricultores associados para diversificar a produção comercializada pela cooperativa, enquanto que para a empresa Natura o objetivo é se firmar no mercado global de cosméticos, adquirindo produtos naturais, indispensáveis para fabricar seus cosméticos da linha Ekos Natura. Além de comprar as amêndoas da cooperativa, a empresa defende que é necessário ter uma maior aproximação com os coletores, como forma de manter um vínculo com fins que certifique o seu discurso de sustentabilidade para as comunidades tradicionais da Amazônia e para manter a floresta em pé. Além disso, é sabido que tais relações facilitam a logística e reduzem os custos de comercialização pela redução de atravessadores.

Pesquisas de Suzuki (2009) apresentam que as famílias fornecedoras destacam o potencial existente como "parceiras" da Natura. O objetivo da Natura, segundo informações oficiais, é “ $[\ldots]$ o desenvolvimento sustentável que consiste em valorizar a agricultura familiar

\footnotetext{
${ }^{3} \mathrm{O}$ aumento da entrega ocorreu devido o lançamento dos cosméticos feito da amêndoa do murumuru, mantendo o estoque do produto.
} 
organizada em cooperativas e o desenvolvimento regional de produtos naturais, evitando o corte de árvores e aproveitar seus frutos como fonte de renda" (SUZUKI, 2009, p. 78).

Apesar desse discurso, segundo as entrevistas realizadas, a Natura não desenvolve nenhum tipo de apoio na organização e gestão na comunidade, nem mesmo projetos de pesquisa e desenvolvimento, ficando como prática somente a compra da matéria-prima, pois as parcerias são estritamente comerciais, assegurando somente a compra da amêndoa das famílias, o escoamento de novos produtos, criando uma fonte de renda complementar da ordem de um salário mínimo por mês.

A coleta da amêndoa murumuru ocorre entre os meses de março a novembro de cada ano, gerando duas entregas anuais de produção. A amêndoa coletada entre os meses de março e julho é entregue na primeira remessa do ano e entre agosto e novembro ocorre a segunda entrega. A coleta é realizada quase diariamente pelos quilombolas/extrativistas da comunidade do Jacarequara. Os coletores se reúnem cada um com seu grupo familiar, ou seja, não acontece a coleta entre famílias.

A área de coleta é de uso comum e as palmeiras são típicas de área de várzea, próximas às áreas da comunidade é banhada pelo Rio Guamá, o que justifica a rica da presença dessa palmeira. Apesar de a coleta ser regular, ainda não há registros de conflitos por área de coleta. É interessante destacar a predominância da presença do marido e da esposa e dos filhos mais velhos nessa etapa de produção, que coletivamente adentram nas matas para efetuar a coleta do caroço do murumuru.

Segundo relatos colhidos em campo, as famílias coletoras alegam que o trabalho de coleta da amêndoa no meio da mata ciliar demanda muito esforço, pois no local da extração existem animais peçonhentos, como cobra, aranha, escorpião e muitos espinhos, típicos da palmeira do murumuru. Além disso, relatam a dificuldade de transporte da produção coletada. Mesmo com os pesares desta atividade, o trabalho envolve muita descontração, reveladas em cantorias, assobios e brincadeiras entres os coletores. Essas práticas de descontração são uma maneira de motivá-los na coleta.

Depois de realizada a coleta, os coletores transportam do interior da mata pela canoa (a remo) ou animais (burro, jumento, cavalo). Aqueles que não possuem nenhum desses meios trazem apoiados na cabeça até a comunidade. Chegando à comunidade, os coletores lavam as amêndoas para facilitar a seleção dos caroços com melhor qualidade para a venda e depois são espalhados em uma mesa confeccionada por eles mesmos, dentro de uma "casa estufa", onde são expostas ao sol por um período de aproximadamente sete dias, período necessário para que a amêndoa se solte da casca do caroço, pronto para a quebra do caroço. 
Após todos os caroços secos e com a amêndoa desgrudada, as amêndoas são armazenadas para aguardar 15 dias antes da entrega com data estabelecida pela empresa Natura para entregar a produção. No processo de quebra da amêndoa são envolvidos todos os membros da família, pois há um prazo de entrega a ser cumprido.

Essa etapa da produção também é uma tarefa que demanda esforço intenso, pois existe um risco de no ato da quebra do caroço pela rigidez de sua casca. Assim, é necessária a utilização de ferramentas pesadas, como martelo e um fragmento de rocha (pedra) como apoio. A falta de prática ou um descuido pode causar lesões nos dedos da mão e nos olhos dos quebradores. Além disso, dificulta ainda mais o processo a exigência da Natura sobre a integridade da amêndoa, que não pode apresentar nenhuma rachadura. No caso de rachaduras, a amêndoa não é classificada para venda.

Não existe na comunidade um local reservado para a quebra do caroço, sendo feita na própria casa dos coletores. O trabalho das famílias se encerra nesta etapa de quebra do caroço, ficando na responsabilidade deles transportarem a produção até a COOMAR, localizada na cidade de Santa Luzia do Pará. Após a entrega na cooperativa, esta fica com a responsabilidade da entrega na sede da empresa Natura localizada na cidade de Benevides, Pará.

A relação entre empresas e comunidades tradicionais para a comercialização de produtos não florestais permite refletir sobre a expansão do capitalismo sob o discurso de produção sustentável dentro de uma lógica de acumulação flexível do capital no espaço amazônico. A inserção dessas parcerias na Amazônia pode remover ou dissolver as relações sociais e as relações de produção tradicionais, ampliando a incorporação de uma lógica de produção capitalista, alterando os modos de vidas tradicionais, mesmo que temporariamente.

\section{CONSIDERAÇÕES FINAIS}

Essa pesquisa buscou responder a seguinte questão: quais os impactos da parceria comercial da empresa de cosméticos Natura na comunidade quilombola Jacarequara na reorganização das relações socioespaciais dos quilombolas?

Do ponto de vista teórico, autores como Benko (2002) e Harvey (2005) mostram que as relações de produção capitalista contemporâneas se flexibilizam e exploram os recursos naturais, na forma de matéria prima, e a sociedade, na forma de apropriação da mais-valia ou da sua produção. As parcerias comerciais são estratégias capitalistas fruto da flexibilização avançada do sistema capitalista. Não podemos limitar nossas análises exclusivamente ao 
desenvolvimento sustentável limitado aos recursos naturais, mas também pensar num desenvolvimento que considere as especificidades das sociedades tradicionais, preservando seus modos de vida no que for de seu interesse.

Quando se pensa em desenvolvimento sustentável na Amazônia, não se pode negar a importância de preservar os modos de vidas tradicionais que dão equilíbrio aos recursos da floresta. É necessário que se reverta o padrão de projetos de desenvolvimento sustentável que visam somente os recursos naturais, ficando os amazônidas excluídos dos discursos e das práticas. $\mathrm{O}$ caso da comunidade Jacarequara nos parece mais um destes.

As comunidades tradicionais, de acordo com Diegues (2004), estão cada vez mais ligadas à busca de sobrevivência e à reprodução de suas identidades. Ocorre que o capitalismo continua a se expandir, seja transformando as relações de produção ou, sem alterá-las, subordinando-as ao seu interesse (OLIVEIRA, 2007). Nesse sentido, é preciso destacar que a inserção dessas parcerias comerciais em comunidades tradicionais da forma como vem ocorrendo alteram as relações de produção, tornando-as sujeitas às práticas comerciais individualistas e ao sabor das oscilações do mercado.

Entendemos como adequado pensarmos propostas parcerias entre empresas e comunidades tradicionais que tenham como estratégia promover não somente a conservação ambiental, mas também melhorar o padrão de vida das sociedades tradicionais, permitindo relações mais autônomas para as comunidades, permitindo aos extrativistas/coletores/produtores a deliberação sobre a viabilidade ou não de cada projeto. Situações de vulnerabilidade incentivam à aceitação de condições quaisquer, facilitando a sujeição das relações de produção tradicionais aos interesses do capital.

Ações voltadas ao desenvolvimento de atividades que aumentem a geração de renda da comunidade, pelo incentivo à agregação de valor de produtos oriundos da amêndoa coletada poderiam ser desenvolvidas, permitindo a maior geração de renda para a comunidade, encaminhando-a para um processo de geração de autonomia. Ao contrário, as relações estabelecidas encaminham-na a um processo de heteronomia, onde a lógica de trabalho e as relações de produção são definidas por aqueles que sequer vivem no território (SOUZA, 2000). São definidas, grosso modo pela Natura, pelo "mercado" e pelos consumidores.

Não podemos deixar de enfatizar que a parceria comercial entre empresa e comunidades tradicionais muito tem contribuído para a manutenção da mata ciliar preservada, ou seja, percebe-se que a floresta foi mantida, mas os animais que se alimentavam da amêndoa do murumuru, que antes ao cair da árvore servia de alimento, agora são obrigados a 
migrarem para outras áreas, pois a amêndoa é coletada o ano inteiro. São vários os impactos que uma parceria comercial pode ocasionar para a sociedade e para a floresta e que não são considerados na implantação do projeto.

O presente trabalho buscou mostrar a inserção das práticas comerciais da amêndoa do murumuru na comunidade quilombola Jacarequara pela empresa do setor de cosméticos Natura. A comunidade sofre diversas carências de recursos, sejam por parte das ações do Estado ou pelas condições das famílias. Natura, podendo a própria comunidade beneficiar o sabonete ou mesmo cremes para o corpo da amêndoa do murumuru, criando alternativas para a juventude quilombola permanecer no seu território, reproduzindo as relações de cooperação e sociabilização e mantendo o equilíbrio dos produtos florestais.

$\mathrm{Na}$ comunidade quilombola Jacarequara observou-se que ainda está distante dos padrões de desenvolvimento sustentável para a sociedade e para a própria floresta. As famílias coletoras convivem com a contradição da abundância dos recursos naturais e, ao mesmo tempo, com a escassez de serviços básicos, como a distribuição de água potável, saneamento básico, educação e saúde de qualidade. Contraditoriamente, essa abundância em recursos naturais é explorada e consumida principalmente por agentes externos. O lucro desses produtos fica com os donos dos meios de produção, no caso, a Natura. Para os quilombolas sobram a tarefa da coleta e da separação da amêndoa, recebendo uma remuneração considerada proporcional ao esforço, segundo os parâmetros da empresa.

Debater a repartição dos benefícios desses produtos florestais não madeireiros entre empresa e a comunidade continua sendo uma tarefa difícil, seja pelo desafio de mensurar tal "esforço", seja por compreender a complexidade das relações. Apesar disso, foi possível concluir que na maioria das vezes as comunidades não são conhecedoras da relevância que o produto coletado tem no que diz respeito ao valor de mercado. Essas discussões não chegam na comunidade, na associação ou no governo do município, cabendo ao lado mais forte da relação, no caso, a Natura, a decisão sobre os preços, prazos e formas de entrega dos produtos.

Com as pesquisas de campo, aliadas às leituras realizadas, conclui-se que a disseminação da informação e o incentivo a articulação permitiriam à comunidade mecanismos de pressão para maior transparência e melhores condições de trabalho, seja demandando remuneração, equipamentos ou estruturas para realização das atividades. As relações sempre penderão para as instituições de maior porte, no entanto, é inegável que o conflito é constante e, com as ferramentas certas, podem pender para o lado dos mais vulneráveis, cumprindo os direitos e respondendo aos interesses das comunidades tradicionais. Considerando a frequência dessas parcerias na Amazônia, é necessário que as 
comunidades tradicionais se articulem em prol de seus direitos e garantias de seus recursos naturais.

\section{REFERÊNCIAS}

ALMEIDA, Rozemberg Ribeiro. Arte, cultura e memória em um povoado quilombola: Jacarequara em pauta. TCC apresentado ao curso de História da Universidade Federal do Pará para a obtenção do grau em Licenciatura e Bacharelado em História. Cametá - PA, 2009.

ANDERSON, A. \& CLAY, J. (org.) 2002. Esverdeando a Amazônia: Comunidades e empresas em busca de práticas para negócios sustentáveis. Instituto Internacional de Educação do Brasil, Ed. Fundação Peirópolis. São Paulo.

ARRUDA, Rinaldo. "Populações Tradicionais" e a proteção de recursos naturais em Unidades de Conservação. In: Ambiente \& Sociedade, ano II, n 5, 1999

BENKO, Georges. Economia, espaço e globalização: Na Aurora do Século XXI. Tradução: Antonio de Pádua Danesi. 3. Ed. São Paulo: Hucitec: Annablume, 2002.

CASTRO, Edna. Escravos e Senhores de Bragança (Documentos históricos do século XIX, Região Bragantina, Pará)/ Edna Maria Ramos de Castro (organização). Belém: NAEA, 2006.

COSTA, Jedival Mauricio \& RICHETTI, Patrícia. Parceria entre empresa e comunidades tradicionais na Amazônia brasileira: processos contemporâneos de mercantilização da cultura e do meio ambiente. Novos Cadernos NAEA. V.13, n.2, p. 261-275, 2010.

DIEGUES, Antonio Carlos S. Biodiversidade e Comunidades Tradicionais no Brasil. São Paulo: NUPAUB-USP, PROBIO-MMA, CNPq, 2000.

Populações Tradicionais em Unidades de Conservação. In: DIEGUES, Antonio Carlos S. O mito do paraíso desabitado nas florestas tropicais brasileiras. In: CASTRO, Edna \& PINTON, Florence (orgs). Faces do trópico úmido: conceitos e questões sobre desenvolvimento e meio ambiente. Belém: CEJUP, UFPA-NAEA, 1997.

HARVEY, D. A produção capitalista do espaço. São Paulo: Annablume 2005. Coleção Geografia e adjacências.

LIMA, Deborah; POZZOBON, Jorge. Amazônia socioambiental. Sustentabilidade ecológica e diversidade social. In: Estudos Avançados n 19 (54), 2005.

MORSELLO, C. 2002. Market Integration and Sustainability in Amazonian Indigenous Livelihoods: the Case of the Kaiapó. Tese ( $\mathrm{PhD})$. School of Environmental Sciences, University of East Anglia, Grã-Bretanha. Disponivel em:<< http://www.parceriasflorestais.org/ >>. 
MORSELlO, C. 2004. Trade Deals between Corporations and Amazonian ForestCommunities under Common Property Regimes: Opportunities, Problems and Challenges. In: The Tenth Biennial Conference of the International Association for the Study of Common Property (IASP), The Commons in an Age of Global Transition: Challenges, Risks and Opportunities. Oaxaca, México. Disponível em: $<<\mathrm{http}: / /$ www.parceriasflorestais.org/ $>>$.

PETERS, C.; ALWYN, M.; GENTRY, H. \& MENDELSOHN, R. O. 1989. Valuation of an Amazonian Rainforest. Nature, 339: 655-656.

OLIVEIRA, Ariovaldo U. Modo de produção capitalista, agricultura e reforma agrária. São Paulo: Labur Edições, 2007. 184 p.

PINTO, Benedita Celeste de Morais. Nas Veredas da Sobrevivência: memória, gênero e símbolos de poder feminino em povoados amazônicos. Belém: Ed. Paka-Tatu, 2004.

SANTOS, Milton. A Natureza do Espaço: Técnica e Tempo, Razão e Emoção. $4^{\mathrm{a}}$ ed. São Paulo Editora da Universidade de São Paulo, 2009

SOUZA, Marcelo L. de. O território: sobre espaço e poder, autonomia e desenvolvimento. In: CASTRO, Iná E. de; CORREA, Roberto L.; GOMES, Paulo C. da C. (Org.). Geografia: conceitos e temas. $2^{\mathrm{a}}$ Ed. Rio de Janeiro: Bertrand Brasil, 2000. p. 77-116.

SUZUKI, G. T. O conceito de sustentabilidade e estratégia empresarial: O caso Natura na Amazônia. Dissertação de mestrado (Núcleo de Altos Estudos Amazônicos - NAEA, Programa de pós graduação em Desenvolvimento Sustentável do Tópico Úmido- PDTU). Universidade Federal do Pará (UFPA). Belém, 2009.

VIEIRA, Paulo Freire; MAIMON, Dália (Org.). As Ciências Sociais e a Questão Ambiental: Rumo à Interdisciplinaridade. Belém: NAEA/UFPA, 1993. 